International Journal of Research in Engineering and Innovation
(IJREI)

\title{
Heat treatment effects on fatigue life of medium carbon steel
}

\author{
Kapil, Puneet Kumar Nema
}

Department of Mechanical Engineering, Madhav Institute of Technology and Science Gwalior

\begin{abstract}
This paper investigated the effect of heat treatment operations on the fatigue resistance of medium carbon steel. Prepared specimens for fatigue testing were subjected to annealing, normalizing and quenching. On comparing the Results annealed specimen had the maximum number of cycles to failure against fatigue with the untreated specimen. Normalizing components have a little improved life. While in case of quenching, there is decrease in fatigue life due to surface cracks on the specimen. (C) 2019 ijrei.com. All rights reserved

Keywords: Heat treatment, Normalizing, Annealing, quenching.
\end{abstract}

\section{Introduction}

Many rotating parts of a machine e.g. turbine, vehicles and rails are often subjected to cyclic loads leading to fatigue. Fatigue failure is of great importance as it is well known that the large percentage of failures in machine elements is due to fatigue. Metal fatigue is caused by repeated cycles of load. It causes progressive localized damage due to fluctuating stresses and strains on the material. From estimates made, over $80 \%$ of failures in machines is the result of fatigue failure [1]. Fatigue failures occur in engineering materials whereby a metal fails when subjected to repetitive dynamic or fluctuating stresses/loads much lower than those required to cause fractures on single applications. Loads which can cause fatigue failure apart from axial can be those in shear or bending [2]. Several research works have been carried out on fatigue behaviors of medium carbon steel, among such works is the work done by D.T. Llewellyn[3] Medium-carbon steels are typically used in large-sized components, machined components, forgings For example bolts, rods, crankshafts, rail and tubing in the automotive industry are generally made of steels with $\sim 0.4 \mathrm{wt} \% \mathrm{C}$ and axles, gears, and components that are required to possess higher wear resistance and higher hardness are frequently made of steels with $\sim 0.5 \mathrm{wt} \%$ C. Oluwole [4] worked on the effect of heat treatment on the damage ratio of corroded ST $60 \mathrm{Mn}$ steel and suggested that manganese steels like ST $60 \mathrm{Mn}$ used for oil pipelines should be heat treated by normalizing before use in order to enhance the fatigue life. Medium-carbon steel is usually referred as to the carbon steel that contains approximately $0.30-0.60 \%$ carbon element content. It balances ductility and strength, and has good wear resistance [5]. The fatigue life can be influenced not only by test conditions and specimen states such as the type of loading applied, mean stress, test temperature, size and shape of the specimen, and surface condition of the specimen but also by metallurgical variables such as hardness, strength, grain size, microstructure, and purity [6-9]. Drawing an S-N curve of a material usually requires fatigue tests to be performed under more than five stress amplitude conditions so at least three experiments are required to be performed under each stress amplitude condition [10]. To obtain the fatigue life and SN curve of a component a large number of experiments with (104 -107 cycles) and about 10-30 days are required.

Angel [9], studied the isothermal formation of martensite induced by static tensile deformation.

\section{Experimental setup and procedure}

The experimental techniques for the project work are listed as:

- Specimen Specification and machine setup

- Heat Treatment

- Fatigue Life Estimation 
The first and foremost job for the experiment is the specimen preparation. The specimen size should be compatible to the machine specifications: We got the sample from medium carbon steel trader. The sample that we got was medium carbon steel AISI1035 \& AISI1045. It is one of the American standard specifications of the medium carbon steel having the pearlitic matrix with relatively equal amount of ferrite and so it has high hardness with moderate ductility and high strength as specified below. So we can state that it is particularly a combination of pearlitic and ferritic mixture. Chemical composition of the specimen is given below.

Table 1: Chemical composition of the specimen

\begin{tabular}{|c|c|c|c|c|c|c|}
\hline $\mathrm{C}$ & $\mathrm{Mn}$ & $\mathrm{Si}$ & $\mathrm{Mo}$ & $\mathrm{S}$ & $\mathrm{P}$ & Fe \\
\hline 0.35 & 0.75 & 0.2 & 0.05 & 0.04 & 0.05 & Balance \\
\hline
\end{tabular}

The specimen is prepared according to the Moore testing machine. For this firstly the samples are cut into pieces from the sheets. The dimensional specification is as shown. As prior to the fabrication, heat treatment should be done because due to heat treatment there are some dimensional changes in the samples. This one is done to maintain the uniformity in the desired samples for further tests.

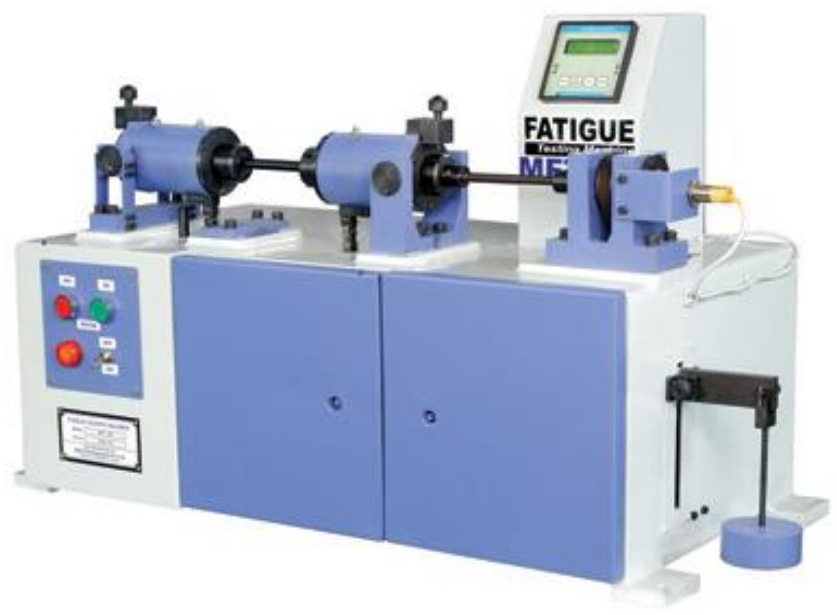

Figure 1: Fatigue testing machine

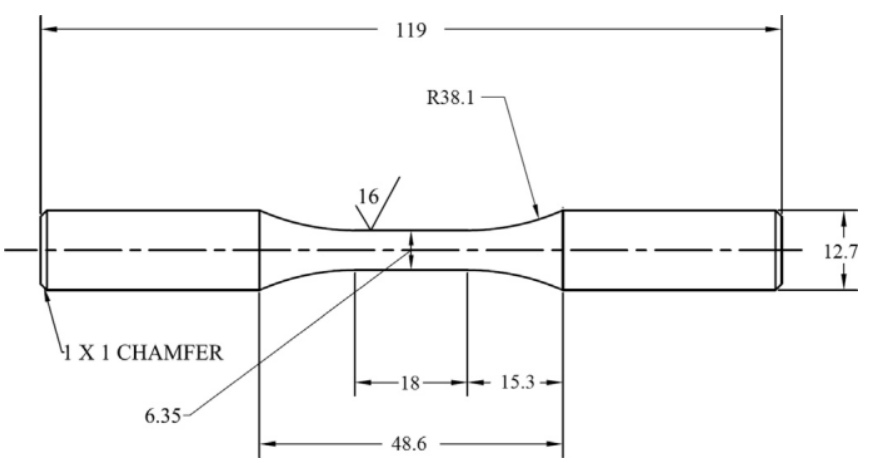

Figure 2: Fatigue specimen size and dimensions per ASTM standard E606/E606M-12 [12]
Medium carbon steel is primarily heat treated to create matrix microstructures and associated mechanical properties not readily obtained in the as-cast condition. As cast grounded substance microstructures usually consist of ferrite or pearlite or combinations of both, depending on substance size and alloy composition. The principle objective of the project is to carry out the heat treatment of medium carbon steel at different temperatures according to heat treatment process diagram and then to compare the mechanical properties. There are various types of heat treatment processes we had adopted.

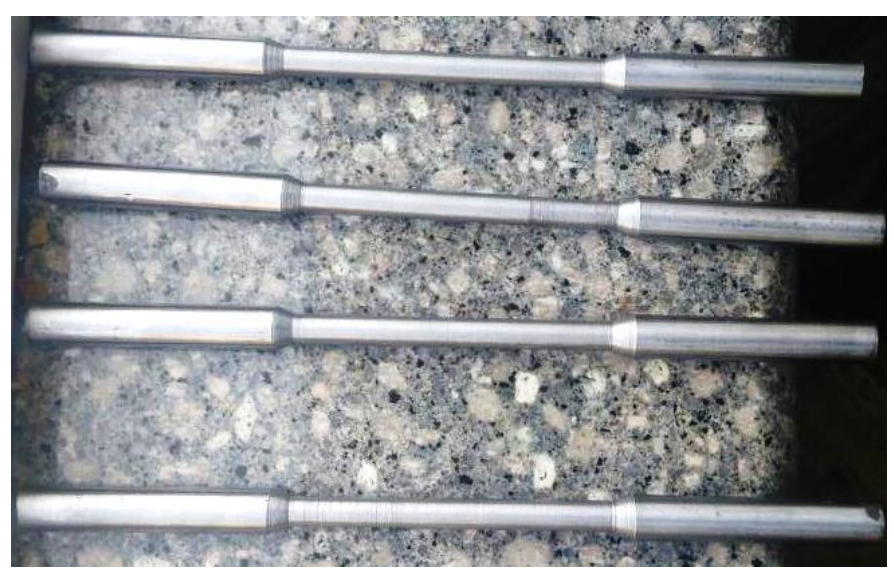

\subsection{Annealing}

Figure 2: Samples before heat treatment

- The specimen was heated to an annealed temperature of $800^{\circ} \mathrm{C}$.

- At $800^{\circ} \mathrm{C}$, the specimen was held for 2.30 hour.

- After soaking for 1hour the furnace was switched off so that the specimen temperature will decrease with the same rate as that of the furnace.

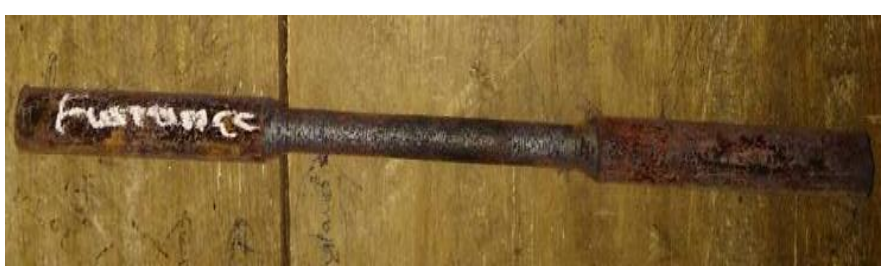

Figure 3: After annealing

The objective of keeping the specimen at $800^{\circ} \mathrm{C}$ for $2.30 \mathrm{hrs}$ is to homogenize the specimen. The temperature $800^{\circ} \mathrm{C}$ lies above A3 temperature so that the specimen at that temperature gets sufficient time to get homogenized.The specimen was taken out of the furnace after 1 day when the furnace temperature had already reached the room temperature as shown in Figure 3. Specimen heated above A3 temperature line and cooled by environmental conditions is called normalizing. This is the important experiment carried out with the objective of the experiment being to induce some amount of softness in the material by heating to a moderate temperature range. First, the some of the specimen were heated to $800^{\circ} \mathrm{C}$ for $2: 30$ hour and then quenched in the water bath maintained at room temp. 


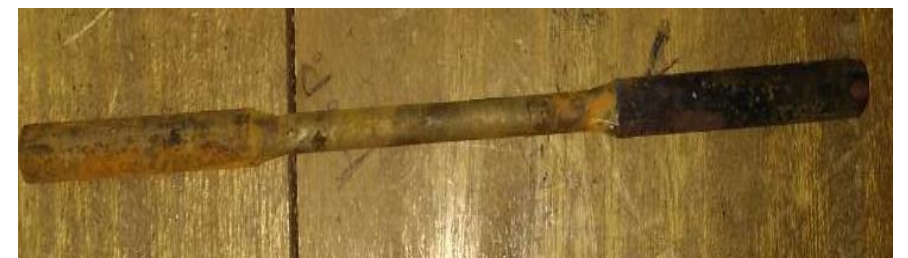

Figure 4: Specimen after quenching

Preventing from oxidation the samples are placed inside the furnace in a container having charcoal. After the specimens got heated to different temperatures for a different time period, they were air cooled. The heat treatment of tempering at different temp for different time periods develops variety of properties within them.

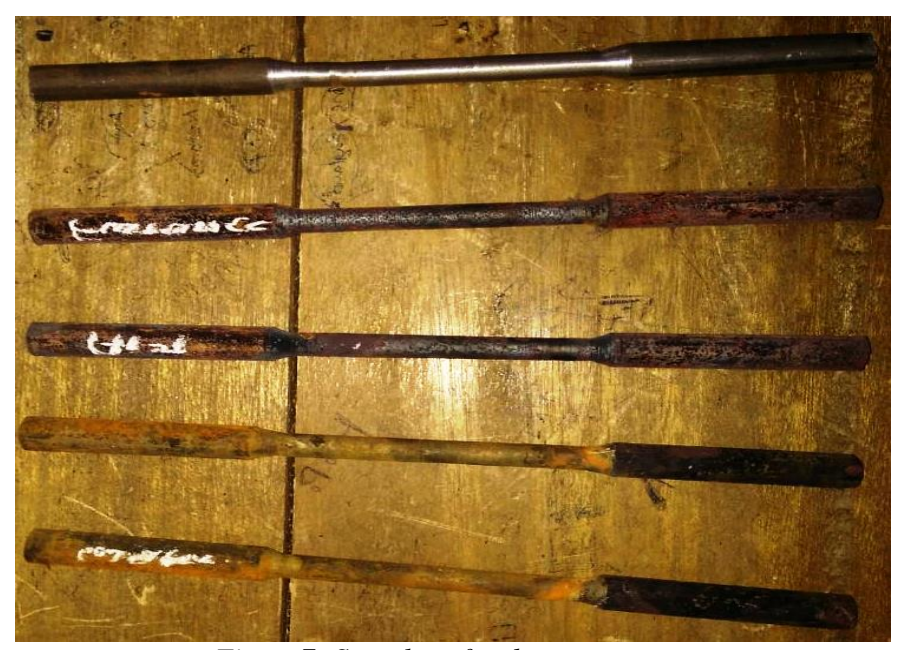

Figure7: Samples after heat treatment

\subsection{Fatigue Life estimation}

Three basic factors are mainly responsible for the fatigue failure. These are as follows:

- A maximum tensile stress of sufficiently high value.

- Large variation or fluctuation in applied stress.

- A sufficiently high cycle for the applied stress.

Processes were carried out at different load condition and estimate the respective fatigue life. Following steps are followed during the experiment

- First polish the sample surface as smooth as possible and observe for any surface defects and deep scratch, machining marks.

- The required dimensions of the specimen were measured.

- Now fit these specimens one by one in the sample holder.

- After fitting. A load of $200 \mathrm{~kg}, 150 \mathrm{~kg}$, and $100 \mathrm{~kg}$ were provided keep the desired load on the seat provided for the loads.

- Switch on the instrument to conduct the fatigue test and record the time for the failure in each case

- Note the appearance of the fractured surface in each case.

\section{Results and discussion}

Load $(\mathrm{P})=200 \mathrm{Kg}$, Length $(\mathrm{L})=10 \mathrm{~cm}$, Diameter $(\mathrm{d})=0.8 \mathrm{~cm}$

Bending Moment $(\mathrm{Mb})=\frac{P L}{2}$

$\mathrm{Mb}=\frac{P * 10}{2}$

$=5 * \mathrm{P} \mathrm{Kgcm},=5 * 200 \mathrm{Kg}-\mathrm{cm},=10000 \mathrm{Kgcm}$

Section module $(\mathrm{Z})=\frac{\Pi d^{3}}{32}$

$=\frac{3.14 * 0.8^{3}}{32}=0.05024 \mathrm{~cm}^{3}$

Bending stress $(\sigma)=\frac{50.93 . * 200}{0.8^{3}}$

$\sigma=19894.53 \mathrm{Kg} / \mathrm{cm}^{2}$

The measured value of number of cycles for a fixed load for various processes is shown in table. The fig. 8 shows the number of cycles for various processes at a fixed load for $0.35 \%$ medium carbon steel and fig. 9 shows the number of cycles for various processes at a fixed load for $0.45 \%$ medium carbon steel. These figure shows that the maximum number of cycles were obtained for annealing heat treatment.

Table 2: Measurement of No of cycles for various processes

\begin{tabular}{|l|l|l|l|l|}
\hline S.N. & Load(kg) & Process & $\begin{array}{l}\mathbf{0 . 3 5 \%} \\
\text { carbon }\end{array}$ & $\begin{array}{l}\mathbf{0 . 4 5 \%} \\
\text { carbon }\end{array}$ \\
\hline $\mathbf{1}$ & 200 & Normal & 18990 & 21140 \\
\hline $\mathbf{2}$ & 200 & Annealing & 23495 & 25400 \\
\hline $\mathbf{3}$ & 200 & Normalizing & 21230 & 24100 \\
\hline $\mathbf{4}$ & 200 & Hardening & 20400 & 22680 \\
\hline
\end{tabular}

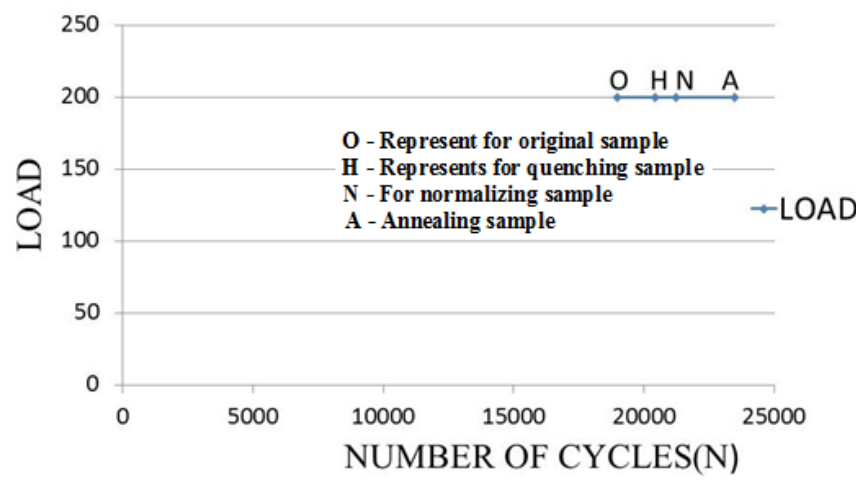

Figure 8: Curves for $0.35 \%$ medium carbon steel

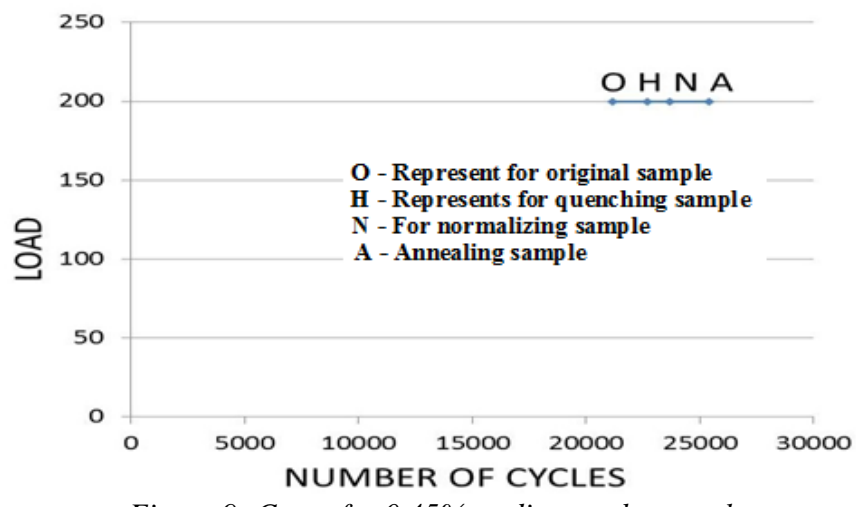

Figure 9: Curve for $0.45 \%$ medium carbon steel 


\section{Conclusions}

$>$ After annealing due to increase in ductility and decrease in hardness the number of cycles increases as compared to original specimen.

After normalizing due to increase in softness and ductility the number of cycles increases as compared to original specimen.

$>$ After hardening due to increase in toughness and strength the number of cycles increases as compared to original specimen.

\section{References}

[1] Rajasekhar K. Micro structural evolution during solidification of austenitic stainless steel weld metals: a color metallographic and electron microprobe analysis study. Mater Charact 1997;38(2):53-65
[2] Peter AT, Vito JC. Fundamental of engineering materials. 1st ed. Englewood Cliffs: Prentice-Hall Inc.; 1985. p. 385-317.

[3] D.T. Llewellyn, R.C. Hudd, Steels: Metallurgy and Applications, 3th ed., Butterworth-Heinemann, Oxford, UK, 1998. 70-25

[4] Oluwole OO. Effect of heat treatment on the damage ratio of corroded ST 60 Mn steel. NSE Tech Trans 2001; 36(4):50-8.

[5] The Wikipedia page on carbon steel, https://en.wikipedia.org/wiki/Carbon_steel\#cite_note-

[6] W. Li, T. Sakai, M. Wakita, S. Mimura, Mater. Sci. Eng. A 552 (2012) 301-309.

[7] M. Sander, T. Müller, J. Lebahn, Int. J. Fatigue 62 (2014) 10-20.

[8] Q. Jiang, C. Sun, X. Liu, Y. Hong, Int. J. Fatigue 93 (2016) 352-362.

[9] X. Liu, C. Sun, Y. Hong, Int. J. Fatigue 92 (2016) 434-441.

[10] ASTM Standard E466-82, Practice for Conducting Constant Amplitude Axial Fatigue Tests of Metallic Materials, ASTM, Philadelphia, 1987.

[11] Angel T. Formation of martensite in austenitic stainless steels: effects of deformation, temperature, and composition. $\mathbf{J}$ Iron Steel Inst 1954;177:165-74.

[12] ASTM Standard E606/E606M_12, Standard Test Method for StrainControlled Fatigue Testing, ASTM International, West Conshohocken, PA, 2012.

Cite this article as: Kapil, Puneet Kumar Nema, Heat treatment effects on fatigue life of medium carbon steel, International Journal of Research in Engineering and Innovation Vol-3, Issue-5 (2019), 339-342. 